\title{
ADDITIONAL SOURCES OF DISTURBANCE PHEROMONE AFFECTING THE CRAYFISH Orconectes virilis
}

\author{
BRIAN A. HAZLETT \\ Department of Biology, University of Michigan \\ Ann Arbor, Michigan 48109 \\ University of Michigan Biological Station \\ Pellston, Michigan
}

(Received October 8, 1987; accepted December 17, 1987)

\begin{abstract}
The responses of individually housed crayfish (Orconectes virilis) were recorded during introduction of water from aquaria containing disturbed or undisturbed animals. When female $O$. virilis were disturbed, form II males assumed low-level altert postures significantly more than when those females were undisturbed. Similar results were obtained when the source animals were female Cambarus diogenes, a sympatric crayfish. When the newt Notopthalamus viridescens was disturbed, the crayfish responses were strong but resembled stress behavior. The responses by crayfish to disturbed vs. undisturbed catfish (Ictalurus natalis) were not significantly different.
\end{abstract}

Key Words-Pheromone, disturbance, crayfish, Orconectes virilis, crossphyletic communication, stress, female crayfish.

\section{INTRODUCTION}

The detection of stressed conspecific individuals has been reported in earthworms (Ressler et al., 1968), several types of molluscs (Landauer and Chapnick, 1981; Sleeper et al., 1980), insects (Levinson et al., 1974), and mammals (Valenta and Rigby, 1968). The responses of crayfish to a chemical or chemicals given off by stressed (but not injured) conspecific individuals have been used to demonstrate the existence of disturbance pheromones (Hazlett, 1985a). Observations (Hazlett, 1985b) have indicated that these pheromones are neither specific to a particular form of stress that a crayfish experiences nor are they 
species specific. Individuals of Orconectes virilis respond to water containing stressed males of $O$. virilis, $O$. rusticus, or $O$. propinquus (Hazlett, 1985b).

Recent work has indicated a number of cases in which chemical communication occurs across phyletic lines. This often is observed in the form of predator detection (Scrimshaw and Kerfoot, 1987; Petranka et al., 1987; Werner, personal communication) and can have both behavioral and morphophysiological consequences for prey animals. The experiments reported herein were designed to look for chemical communication across major phyletic lines as well as to examine the question of release of disturbance pheromones by female crayfish.

\section{METHODS AND MATERIALS}

Experiments were conducted at the University of Michigan Biological Station near Pellston, Michigan, during July and August 1986. Methods were identical to those described earlier (Hazlett, 1985a, b). The crayfish tested were all individuals of Orconectes virilis collected from either Douglas Lake or the Maple River. Test individuals were housed in individual 10-gallon aquaria that were visually isolated. Each test crayfish was provided with a rock burrow and was tested with just one type of water on any given day. Water was introduced via a peristaltic pump at the rate of $20 \mathrm{ml} / \mathrm{min}$ for a test period of $8 \mathrm{~min}$.

The sources of water introduced to the test individuals of $O$. virilis were aquaria that had been filled partially with untreated, well-aerated water from Douglas Lake and in which one or more individuals of the source animals had been living for two to four days. The types of source animals were two species of crayfish and two species of aquatic vertebrates: female crayfish in a different genus (Cambarus diogenes), female crayfish of the same species (O. virilis), members of a school of young yellow bullhead catfish (Ictalurus natalis) that had been collected in Douglas Lake near Sedge Point, and two individuals of the aquatic phase of the red-spotted newt (Notopthalamus viridescens) collected in East Point Pond near Douglas Lake. The two latter species were chosen on the bases of being taxonomically unrelated to crayfish, not common predators of adult crayfish, and cooccurring with the test species.

For the tests when the source animals were female $O$. virilis, all of the test crayfish were male $O$. virilis, which were form II, the sexually inactive form of cambarine crayfish (Word and Hobbs, 1958). In the other tests, both form I males and female $O$. virilis were utilized.

For each type of source animal, water was introduced to resting, undisturbed test animals under two conditions: (1) when the source animals appeared quiet and undisturbed and (2) when the source animals were disturbed by a simulated predator (chased by an aquarium net). All statistical tests compared 
the responses shown during introduction of water from the disturbed vs. undisturbed condition for a given type of source animal.

The behavior patterns recorded have been described earlier (Hazlett, 1985a, b) and involved three positions (raised, neutral, lowered) of three body parts (chelipeds, cephalothorax, abdomen). Earlier work showed that the primary response by crayfish to disturbance pheromones was assumption of a neutral posture. Therefore the data compared in this study are the number of seconds spent by test crayfish with any body part in the neutral position. Because a number of the comparisons involved data sets with unequal variance, the nonparametric median test was used for statistical comparisons. Not all the test animals were used with both disturbed and undisturbed water, thus paired statistical tests were not used.

\section{RESULTS}

The reactions of test crayfish during the introduction of water from different sources are summarized in Table 1. The strongest difference in behavior patterns shown by individuals of $O$. virilis to water from disturbed vs. undisturbed animals was in the case of the salamander Notopthalamus viridescens. The crayfish showed no response (remained in the lowered posture typical of resting animals) when water containing undisturbed newts was introduced. When the newts were disturbed, the reactions were quite rapid and unusual. Although the positions assumed by the crayfish were categorized as "neutral," the postures of the chelipeds and walking legs were not the same as those exhibited during introduction of water from other stressed animals (Hazlett, 1985b). The angles between limb segments were unusual and could best be described as contorted. Rather than appearing to be on "low-level alert" (Hazlett, 1985b), the crayfish behaved as if in a distressed state themselves.

Table 1. Average Number of Seconds during Observation Periods Spent by Individuals of $O$. virilis with ONe or More Parts in Neutral Position when WATER FROM VARIOUS SOURCES WAS INTRODUCED"

\begin{tabular}{llccc}
\hline & & \multicolumn{2}{c}{ Mean No. seconds } & \\
\cline { 3 - 5 } Source of water & $N$ & Undisturbed & Disturbed & $\begin{array}{c}P \text { from median } \\
\text { test }\end{array}$ \\
\hline Notopthalamus & 14 & 0 & 196 & 0.0003 \\
lctalurus & 36 & 61 & 116 & 0.1904 \\
Cambarus & 14 & 41 & 104 & 0.0285 \\
O. virilis & 23 & 52 & 111 & 0.0291 \\
\hline
\end{tabular}

\footnotetext{
${ }^{\prime} \mathrm{N}$ represents the total number of tests with a particular source.
} 
The responses shown to disturbed and undisturbed bullhead catfish were not significantly different from one another (Table 1). While the crayfish tended to assume neutral postures more frequently when water from disturbed catfish was introduced, the difference was not significant.

In the case of water from disturbed and undisturbed female crayfish of the species Cambarus diogenes, the responses shown by individuals of Orconectes virilis were significantly different (Table 1). The crayfish assumed the neutral posture much more frequently when water from an aquarium containing disturbed $C$. diogenes was introduced. In a similar fashion, water from female conspecifics elicited different responses on the part of form II male $O$. virilis, depending upon the state of the female crayfish (Table 1). Form II males assumed one of the neutral postures for more of the observation period during the introduction of water from disturbed female conspecific individuals compared to undisturbed individuals.

\section{DISCUSSION}

The observation that crayfish of one species (Orconectes virilis) react to chemicals from a variety of species of disturbed animals would seem to strengthen the idea (Hazlett, 1985b) that the chemical(s) involved is not very specific. Production of a chemical or class of chemicals that induces low-level alert in totally unrelated individuals points toward the communication resulting from the detection of a chemical that occurs simply from increased activity on the part of another animal. Neither the conditions leading to the increase in activity nor the type of animal involved appear to be critical. While more experiments with crayfish as recipients are needed to test the generality of this suggestion, what may be of more widespread importance is the possibility that whole communities of aquatic animals could cue in on potentially detrimental situations by responding to (the chemical results of) a disturbance to any member of the community.

It was noted earlier (Hazlett, 1985b) that the lack of a clear response by male crayfish to disturbed female crayfish was puzzling and perhaps the result of confounded chemical messages. That is, introduction of water from disturbed female conspecifics could produce stimulation of males with both sex pheromones (Hazlett, 1985a) and disturbance pheromones. Form II male crayfish are said to be sexually inactive, thus they should be less "confused" by reception of any female sex pheromone. The results of this study indicate that when the chemical message channel is simplified (by use of form II males), the production of disturbance pheromones by females is demonstrable. This was also shown by the response differential shown to waters from disturbed and undisturbed females of the genus Cambarus. While there appears to be some crossspecies detection of sex pheromones within the genus Orconectes (Tiemey and 
Dunham, 1982), the results reported here would indicate little confusion via sex pheromones across genera.

The responses of the crayfish to water from disturbed newts appeared qualitatively different from the responses to other disturbed animals. The newts may have been giving off a toxin (Pough, 1971), rather than a pheromone in the narrow sense. The lack of a clear differential in response to bullhead catfish by crayfish was a bit surprising given the established response by catfish to disturbance (Al-Hassan et al., 1985; Todd et al., 1967). While it is possible that the "undisturbed" catfish in these tests were not really undisturbed, the demonstration of cross-phyla detection of a nontoxic disturbance chemical remains for future work. It is crucial for such tests that laboratory conditions allow maintenance and observation of undisturbed individuals of both the recipient and source species.

\section{REFERENCES}

Al-Hassen, J.M., Thomson, M., Criddle, K.R., Summers, B., and Criddle, R.S. 1985. Catfish epidermal secretions in response to threat or injury: A novel defense response. Mar. Biol. 88:117-123.

Hazlett, B.A. 1985a. Chemical detection of sex and status in Orconectes virilis. J. Chem. Ecol. 11:181-189.

HazLetT, B.A. 1985b. Disturbance pheromones in the crayfish Orconectes virilis. J. Chem. Ecol. 11:1695-1711.

LANDAUER, M.R., and CHAPNICK, S.D. 1981. Responses of terrestrial slugs to secretions of stressed conspecifics. Psychol. Rep. 49:617-618.

Levinson, H.Z., Levinson, A.R., and Maschwitz, U. 1974. Action and composition of the alarm pheromone of the bedbug, Cimex lectularis L. Naturwissenschafien 61:684-685.

Petranka, J.W., Kats, L.B., and SiH, A. 1987. Predator-prey interactions among fish and larval amphibians: Use of chemical cues to detect predatory fish. Anim. Behav. 35:420-425.

Pough, F.H. 1971. Leech-repellent property of eastem red-spotted newts, Notphthalmus viridescens. Science 174:1144-1146.

Ressler, R.H., Cialdini, R.B., Ghoca, M.L., and Kleist, S.M. 1968. Alarm pheromone in the earthworm Lumbricus terrestris. Science 161:597-599.

SCRIMSHAW, S., and KERFOOT, W.C. 1987. Chemical defenses of aquatic organisms: Beetles and bugs. pp. 240-262, in W.C. Kerfoot and A. Sih (eds.). Predation, Direct and Indirect Impacts on Aquatic Communities. University Press New England, Hanover, New Hampshire.

Sleeper, H.L., Paul, A.J., and Fenical, W. 1980. Alarm pheromones from the marine opisthobranch Navanx inermis. J. Chem. Ecol. 6:57-70.

TierneY, A.J., and Dunham, D.W. 1982. Chemical communication in the reproductive isolation of the crayfishes Orconectes propinquus and Orconectes virilis (Decapoda, Cambaridae). $J$. Crust. Biol. 2:544-548.

Todd, J.H., ATEMA, J., and Bardach, J.E. 1967. Chemical communication in social behavior of a fish, the yellow bullhead (Ictalurus natalis). Science 158:672-673.

VALENTA, J.G., and RIGBY, M.K. 1968. Discrimination of the odor of stressed rats. Science 161:599-601.

Word, B.H., and HobBs, H.H., JR. 1958. Observations on the testis of the crayfish Cambarus montanus acuminatus Faxon. Trans. Am. Microsc. Soc. 77:435-450. 